\title{
Development of Learning Media Android-Based for Physical Education with the Topic of Illicit Drugs in Facing the New Normal Era
}

\author{
Bilma Adhiono ${ }^{1}$, Eddy Purnomo ${ }^{2}$ \\ \{bilmagtg@gmail.com ${ }^{1}$, eddy_purnomo@uny.ac.id $\left.{ }^{2}\right\}$ \\ Department of Sports Science, Yogyakarta State University, Sleman, Yogyakarta, Indonesia
}

\begin{abstract}
Teaching material about drugs, data showed that student score were lower. Passive students in the learning process tend to exhibit idleness in school duties and reluctant to pay much attention to learning. There is a plethora of factors that plague the ineffective of material delivery to the beneficial. The lack of supporting media in teaching, the disparity in teaching material in schools, inequality in the distribution of facilities, scarcity of professional teachers. The present study wants to intervene and help the learning process to overcome such shortcomings by introducing a certain learning application known as Smart Application Creator 3 (SAC 3). Based on the validation results, construct validation by material experts is $75 \%$, content validation by material experts is $79.41 \%$, validation by media experts is $90.63 \%$, This media is stated to be very interesting, seen from the results of the trial questionnaire, it is found that a percentage of $81.11 \%$.
\end{abstract}

Keywords: Android, learning media, smart application creator 3, drugs.

\section{Introduction}

Online learning in the new normal era of the COVID-19 pandemic especially in physical education has changed drastically and has a different learning environment than the previous learning approach as conventional learning [1]. For instance, before the inception of the pandemic in the year 2020 and previously, in physical education, learning allowed for direct and face-to-face communication/interaction and also facilitate the freedom to learn individually or in groups [2]. Online learning is a new trending learning approach performed at a distance/virtual environment using technology together with an internet connection [3]. One of the technologies mostly used is the integration of Android devices. According to the online Cambridge dictionary, android is an operating system (= a set of control programs) used mainly for mobile devices (= phones and small computers) that uses control by touching the screen. The success of the android devices is inseparable from their open-source nature, that is, can provide free software source code so that developers can develop, distribute, and duplicate it without having to pay for any license [4]. Additionally, Android has provided both paid and free apps by Android developers to make it easier for users [5]. Then, together with the rapid pace of development of science and technology, it is believed that every human being specifically students to be able to react quickly and consciously to all these developments and to keep up with them. This technological development had a positive 
impact on the achievement and implementation of learning during the contemporary COVID19 pandemic [6].

Based on the results of the needs analysis yielded from a survey carried out on 25 physical education instructors in Belitung, seems like these individuals already have an operating Android smartphone. However, some of them lack skills in how to incorporate and use them optimally in education. As result, the learning with the conventional system applied in physical education in terms of immersing and use of learning media is still ineffective [7]. To this end, it can be developed again in the wake of making the learning more variant and dynamic and subsequently learner can learn independently.

Based on the researcher's experience while teaching at SMA Negeri 1 Gantung as a permanent teacher in the lesson of physical education on Narkoba (narkotika, psikotropika, dan obat terlarang) or teaching material about illegal drugs, the researcher came to realized that in such lesson, data showed that student scores were lower. To that said, teaching-learning needs to be improved for the sake of all of us. Despite unsatisfied achievement in the lesson, the lack of interest and motivation to actively engage in taking physical education learning material on drugs was reported [8]. According to [9], motivation is acting to do something. Those who want to participate vigorously and actively are called motivated, conversely, they described those who do not have a motive or inspiration to take any action as amotivated learners [10]. Passive students in the learning process tend to exhibit idleness in school duties and reluctant to pay much attention to learning [11]. As for drawbacks, this has negative impacts on students learning outcomes in general and in illegal drug material in particular. Such paucity in learning motivation is merely due to the ineffectiveness of teachers' delivery material approach since it is limited to dealing with the student worksheet. Meaning that intervention in form of variation in the learning system is of paramount importance. The integration of illegal drug material is a salient asset for students' knowledge acquisition as fortifying themselves from illegal drugs effects on their life and the. There are a plethora of factors that plague the ineffective of material delivery to the beneficial, some of which among others is the lack of supporting media in teaching, the disparity in teaching material in schools, inequality in the distribution of facilities, scarcity of professional teachers, and so forth [12]. In tandem, we notice here that, the presence of these factors latterly highlighted in schools largely contributes to attracting student's attention since the material about illegal drugs is taught in a broad scope. Understanding a certain theory for both these teachers and students is manifestly from consulting textbooks and mostly is not easy to relate or marry up students' needs [13].

The present study wants to intervene and help the learning process to overcome such shortcomings by introducing a certain learning application known as Smart Application Creator 3 (SAC 3). The type of research is a profile of innovation as teaching media in physical education attributed to the topic of illegal drugs in schools. As a reminder, for grade ten $(\mathrm{X})$ high school students, especially in physical education, the content of this material has been designed and available in the curriculum [14]. The SAC 3 application has several advantages over other applications, including; 1) it can be installed or created without advanced programming knowledge, 2) can be utilized to export project html5, 3) display or interface is easy to understand, and 4) does not require a big size of RAM (Random Access Memory) [15] Apart from the advantages of SAC 3 audited above, the SAC 3 apps are also very easy to use especially for active teachers. By using this application, the teacher would be able to be creative effectively in making more innovative learning media. Based on these strengths, the researcher was interested in introducing and developing learning media using SAC 3 application. 
Nowadays, students are getting learning resources from the projector screen, teacher explanations/material clarification, and synthesizing learning lessons in personal notes [16]. As a result, the level of student intuition in carrying out learning activities independently, maximize understanding and develop themselves the material administrated/received. In daily teaching occurrences, students are seen as passive and have a low interest in reading [17]. For this intervention or solutions are needed to overcome these problems. The development of Android-based application media is a solution to help students and teachers in learning activities that have the aim of improving students' abilities in understanding material, increasing activity in the classroom, and increasing reading interest [18]. With the SAC 3 android based application media, students are expected to be able to carry out learning activities independently with or without the presence of the teacher. Learning is expected to be easier and smoother without taking the teacher's time to explain the material.

In addition to providing learning about illegal drugs in school programs, the SAC 3 media that will be developed are also expected to be able to provide effective learning and as a useful tool for opening a little insight in developing meaningful learning media for teachers. The efficacity and portability of Android devices would be more practical to be used anywhere and anytime and save money indeed, then it can make life learning easier for students to engage actively in learning.

\section{Method}

The method used in this research is known as the Research and Development or (R\&D) model. The development model in designing and making this Android-based for physical education learning media uses the ADDIE development model. By definition, the ADDIE model is an acronym for Analysis, Design, Development, Implementation, and Evaluation [19]. The research was conducted for 6 months starting from July 28 to December 20, 2020, which was conducted at public and private high schools throughout the island of Belitung, in Indonesia. The research subjects were Physical Education teachers along with selected students on the same Island. While the subject of field trials was carried out on high state school students of ten grade at Gantung school.

Shortly, for the ADDIE model, this approach is an abbreviation that stands for Analyze, Design, Develop, Implement and Evaluate. During the analysis stage, it consists of consulting and analyzing the content of the subject matter, analyzing student characteristics, without forgetting analyzing teaching supporting media. Also, the second state is known as design; meaning that making a research design is mandatory. The design stage consists of the learning achievement and media development strategy. The next stage after the research design is the development stage. Development in the ADDIE model is a process of realizing a design that has been designed into a real one. That said, during this process, everything needed or anything that can support the new product preparation process should be scrutinized and elucidated as a whole. In short, the development state consists of both the development process and the results [20]. As the implementation is concerned, is the stage for implementing the system or the program being developed. Normally, at this stage, the product being developed should undergo the tried-out process of the field, validate by material experts, media experts as well as teachers and students. The last stage in the ADDIE model in research and development is the evaluation. Broadly, evaluation is a process to determine whether the product that has been suggested and designed meets the eligibility standard requirements 
before being used/applied. The evaluation stage consists of data collection, media improvement, and finished products.

In this study, the trial design was carried out in 4 stages only, namely the material expert to determine the construct and content validation. Furthermore, the media expert to find out the feasibility level of the media then tested on respondents as many as 25 sports teachers from East Belitung in the wake of determining the level of face validity. Research subjects in this research and development study are high school sports teachers in the province of Bangka Belitung along with their students. While the objective of this research and development is learning media with application-based SAC 3 for Physical Education subjects with the topic of illegal drugs.

The type of product trial data used in the research and development of learning media based on Android applications for the topic of Narcotics is quantitative data. Quantitative data were obtained from distributing questionnaires to expert judges, a trial test administered to students as the research respondents. The data harvested will then be processed and used as a basis for assessing the feasibility of the application product being developed. The instruments used in data collection in this research and development was in form of a questionnaire on the topic of illegal drugs as one of school learning material for high school student. The purpose of using this questionnaire is to obtain quantitative data for the perfection and feasibility of the resulting application program. Data collection was carried out at the product trial stage. The type of questionnaire used in this study was a semi-closed questionnaire using a Likert scale [21].

For data analysis, the descriptive method was employed. This method of descriptive especially in the statistic is an analysis used to test quantitative variables thorough description of what is obtained from the field [22]. The descriptive method is a method in examining the status of a group of people, an object, a context, a system of thought, or a group of events in the present. The purpose of this descriptive study is to describe or describe systematically, factually, and accurately the facts, properties, and relationships between the phenomena being investigated. According to [23], descriptive analysis of data is descriptively used to describe the data that has been collected as is and is not used to retrieve statistics. Data processing techniques using Likert scale measurement.

Stevany Kii Londong et al., (2019) explained that the Likert scale is mostly used to measure the attitude, opinion, perceptions of individuals about a specific social phenomenon. This type of scale is believed to provide alternative answers to social instruments with gradations from very positive to very negative. The consideration of choosing this scale is because it makes it easier for respondents to choose answers. The answer criteria were administered to respondents using the Likert scale model. The research subjects were then asked to use entirely the application program and directly in class. Respondents are required to provide/choose one of the options from the alternative answers provided. 


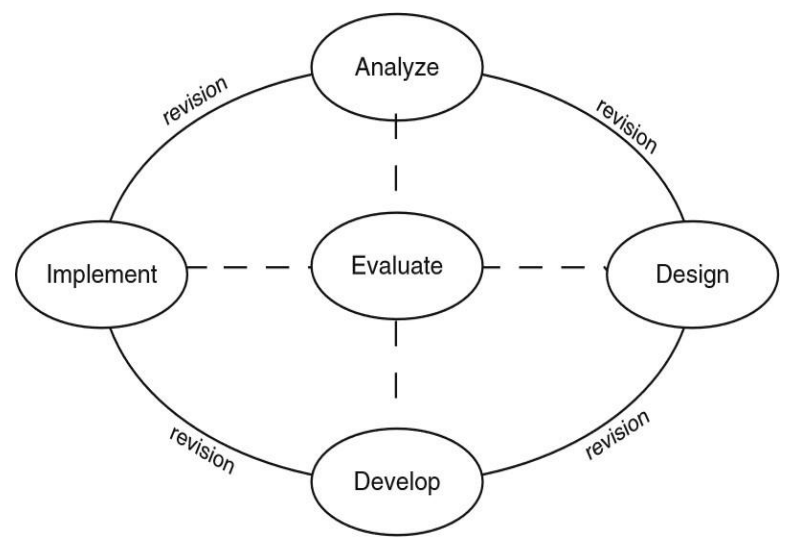

Fig. 1. ADDIE cycle model

Source: [25] \& Mulyatiningsih (2011)

\section{Result and Discussion}

The development result is presented in form of a short discussion of the results that have been carried out by the researcher based on the data and facts that have been obtained. This section compiles the results of needs analysis, design, development, expert validation results, implementation results, and evaluation results.

\subsection{Result of need analysis}

The needs analysis was executed in order to find out whether the development of instructional media on the topic of illicit drugs was needed to support the learning process. After addressing all data at this stage, there are three results are obtained as results from analysis of drug topic subjects, results of analysis of student characteristics, and then results of analysis of supporting media (software and hardware). The results of the analysis of sports subjects on the topic of drugs were obtained based on the 2013 curriculum in the syllabus of Physical Education subjects including 1) Identifying types of drugs, 2) Analyzing the dangers of drugs and psychotropic use against oneself, family, and the community in general. 3) Presenting the results of the identification of the dangers of drug use.

The characteristic analysis stage is the initial stage to determine whether the development of instructional media for sports subjects on the topic of drugs is necessary. The needs analysis was carried out on 25 sports teachers at Belitung. The results of the needs analysis obtained by researchers include: 1) In point 1 about the ownership of an android smartphone for each individual. It can be seen from 25 respondents who chose yes with a percentage of $100 \%$. This means that all respondents have an android smartphone. 2) In point 2 regarding the use of a laptop or Android smartphone for the maximum benefit of education. It can be seen that 18 out of 25 respondents chose yes with a percentage of $85 \%$ and 4 out of 25 respondents chose no with a percentage of $15 \%$. This means that teachers have used laptops and Android smartphones for the maximum benefit of education. 3) In point 3 about the difficulties in delivering sports learning material on drug topics, it can be seen that 12 out of 25 respondents 
chose yes with a percentage of $50 \%$, and 13 out of 25 respondents chose no with a percentage of $50 \%$. This means that some of the teachers still have difficulty delivering lessons on the topic of drugs. 4) In point 4 about the presence of media in the same topic, it can be seen that 2 out of 25 respondents chose yes with a percentage of $10 \%$, and 20 out of 25 respondents chose no with a percentage of $90 \%$. This means that in teaching lessons on the topic of drugs there is still no learning media with the SAC 3 application. 5) In point 5 about the effect of using learning media with the SAC 3 application during the teaching process, seems like 18 out of 25 respondents chose yes with a percentage of $85 \%$, and the 4 remaining individuals chose no with a percentage of $15 \%$. This means that the provision of learning with the SAC 3 application media on drug topics has a significant effect on learning. 6) In point 6 about the respondent's feelings if there is learning media in learning sports on the topic of drugs, it has been found that from 20 respondents all chose yes with a percentage of $100 \%$. This means that all respondents will be happy if there is an Android application-based learning media with SAC 3 on the topic of drugs. 7) In point 7 about the appropriateness of using android applications as a learning medium in sports subjects with the topic of drugs, seems that 24 out of 25 respondents chose yes with a percentage of $96 \%$ and 1 in 25 respondents chose no with a percentage of $4 \%$. This means that most respondents agree with the use of android applications as sports learning medium on the topic of drugs. 8) In point 8 about the experience of using similar learning media in learning activities, results showed that 6 out of 25 respondents chose yes with a percentage of $25 \%$, and 19 out of 25 respondents chose no with a percentage of $74 \%$. This means that most teachers seldom used similar learning media in learning activities. 9) In point 9 regarding the use of learning media based on Android applications, it is appropriate for use in Physical Education learning on the topic of Drugs. It is viewed that 18 out of 25 respondents chose yes with a percentage of $90 \%$ and 2 out of 25 respondents chose no with a percentage of $10 \%$. This means that the Android applicationbased learning media is suitable for use in Physical Education learning on the topic of Narcotics.

\subsection{The result on design stage}

Based on the ADDIE development model procedure used by the researcher, there is a design process that aims to determine the initial design of a product that is being developed. The development of learning media based on Android applications includes learning outcomes and development strategies. Learning outcomes contain the competencies that exist in each learning activity and the results of this development strategy are in the form of storyboards which will be used as a guide in the process of making the learning media application.

\subsection{The result on development stage}

After carrying out the design stages by making learning media to determine the storyboard, the next step was the process of making the learning media application and an android application-based learning media that would be produced on the topic of illegal drugs. In development activities, there was a process in development and the results of this development. The development process includes the preparation of learning material on illegal drugs and Smart Apps Creator 3 software, the implementation of the media creation process according to the design previously made, and the product editing process, namely the process of adding or updating what is needed. For example, the material, display, or other components in the module application, while the results of media development are in the form of the main 
menu display consisting of several buttons such as 1) Guide, containing instructions for using SAC 3 based on Android applications by teachers and students. 2) Competence, contains core competencies, basic competencies, indicators of competency achievement, and learning objectives. 3) The material consists of several menus, namely concept maps, dangers of drug abuse, psychiatric hazards, dangers to the community environment, tips on avoiding abuse, and a summary. 4) Practice questions/quizzes, assessments, answer keys. 5) Reference and reference list. 6) Profile, containing the identity of the developer and supervisor who has helped in the process of developing an android application-based module on the topic of illegal drugs. 7) Exit the application interface using the back button that is already available on the respective android.

\subsection{Content validation by experts}

Content validation through expert judgment is defined by [26] [27] as an informed opinion from individuals with a track record in the field who are regarded by others as qualified experts and who can provide information, evidence, judgments, and assessments. Thus, validation of printed modules by material experts, there are two validations carried out by material experts, namely validation of the content or module content and constructs validation. The variables which are aspects of the observation regarding the print module can be presented in table 1 and table 2 below.

Table 1. Result of instrument construct validation or Media Arrangements for SAC 3 application

\begin{tabular}{clcc}
\hline No & \multicolumn{1}{c}{ Aspects to score } & $\begin{array}{c}\text { Percentage } \\
(\boldsymbol{\%})\end{array}$ & Classification \\
\hline 1 & Instruction for using the proposed media. & 75 & Enough \\
2 & Concept map of learning. & 75 & Enough \\
3 & The student competency to achieve. & 100 & Valid \\
4 & Systematic consistency of material in the learning & 100 & Valid \\
& activity. & 75 & Enough \\
5 & Serving material using media & 100 & Valid \\
6 & Summary & 75 & Enough \\
7 & Student worksheet at the end of learning activity & 100 & Valid \\
8 & Key answers/keywords for student's worksheet & 75 & Enough \\
9 & Introduction & 75 & Enough \\
10 & Referencing/References & 75 & Enough \\
\hline
\end{tabular}

Based on table 1 depicted above here regarding the product feasibility level, it has been found that the average percentage of all aspects obtained from construct validation by material experts was equal to $75 \%$. With these data, it said that the description of the new product fulfills the eligibility level criteria, but revisions need to be made according to the advice of material experts. 
Table 2. Results of instruments Content Validation or Media Contents for SAC 3 application

\begin{tabular}{clcc}
\hline No & \multicolumn{1}{c}{ Aspects to score } & $\begin{array}{c}\text { Percentage } \\
(\mathbf{\%})\end{array}$ & Classification \\
\hline 1 & The completeness of the material. & 100 & Valid \\
2 & Material extension. & 100 & Valid \\
3 & Depth of material & 75 & Enough \\
4 & Consistency/accuracy of concept and definition. & 75 & Enough \\
5 & Data and fact accuracy & 75 & Enough \\
6 & Relevance of examples and cases & 75 & Enough \\
7 & Relevance of image/figures, diagram, and & 75 & \\
& illustration. & & Less \\
8 & Terms Accuracy. & 50 & Enough \\
9 & Nurturing curiosity in learners & 75 & Enough \\
10 & Creating an opportunity to generate questions & 100 & Valid \\
11 & The accuracy of the sentence structure & 75 & Enough \\
12 & The effectiveness of the sentence & 75 & Enough \\
13 & The stickiness of the term/concept. & 75 & Enough \\
14 & Understanding of messages and information. & 75 & Enough \\
15 & The ability to motivate students & 75 & Enough \\
16 & Grammatical accuracy. & 100 & Valid \\
17 & Spelling accuracy & 79,41 & Valid \\
\hline & Cumulative mean & & \\
\hline
\end{tabular}

From the results depicted in table 2 regarding the product feasibility level, it was found that the average percentage of all aspects obtained from content validation by material experts is $79.41 \%$, declared feasible on the description of the product eligibility level criteria, but revisions need to be made according to the advice of material experts.

\subsection{Media expert validation results}

Validation of the module application by media experts, the variables that become aspects of observations about the quality of learning media can be presented in table 3 below.

Table 3. Media Expert Validation Results

\begin{tabular}{|c|c|c|c|}
\hline No & Aspects to score & $\begin{array}{c}\text { Percentage } \\
(\%)\end{array}$ & Classification \\
\hline & Introduction & & \\
\hline 1 & The clarity of the new application. & 100 & Valid \\
\hline 2 & $\begin{array}{l}\text { Easiness of application title in providing an } \\
\text { overview of the media. }\end{array}$ & 100 & Valid \\
\hline 3 & Clarity of operation guide & 100 & Valid \\
\hline 4 & $\begin{array}{l}\text { Easy operation guide } \\
\text { User control }\end{array}$ & 100 & Valid \\
\hline 5 & Control sequence accuracy & 100 & Valid \\
\hline 6 & Navigation button layout consistency & 100 & Valid \\
\hline 7 & $\begin{array}{l}\text { Ease of use of buttons. } \\
\text { Application interface }\end{array}$ & 75 & Enough \\
\hline 8 & $\begin{array}{l}\text { Consistency of layout proportions (text and image } \\
\text { layout) }\end{array}$ & 100 & Valid \\
\hline
\end{tabular}




\begin{tabular}{|c|c|c|c|}
\hline 9 & $\begin{array}{l}\text { The colors used on the layer page are comfortable } \\
\text { to see. }\end{array}$ & 75 & Enough \\
\hline 10 & The accuracy of the background selection & 100 & Valid \\
\hline 11 & The colors used on the background page are & 100 & Valid \\
\hline 12 & $\begin{array}{l}\text { comfortable to see } \\
\text { The accuracy of the background selection }\end{array}$ & 100 & Valid \\
\hline 13 & The menu is easy to understand & 100 & Valid \\
\hline 14 & Sound/audio quality & 100 & Valid \\
\hline 15 & Video display quality & 75 & Enough \\
\hline 16 & $\begin{array}{l}\text { Ease of use of terms. } \\
\text { Application Help }\end{array}$ & 100 & Valid \\
\hline 17 & Detailed and complete instructions for use & 100 & Valid \\
\hline 18 & Easy access to assistance & 75 & Enough \\
\hline 20 & $\begin{array}{l}\text { Clarity of application instructions } \\
\text { Multimedia design principles }\end{array}$ & 100 & Valid \\
\hline $\begin{array}{l}21 \\
22\end{array}$ & $\begin{array}{l}\text { Presentation of material using more than one } \\
\text { media }\end{array}$ & $\begin{array}{l}100 \\
100\end{array}$ & $\begin{array}{l}\text { Valid } \\
\text { Valid }\end{array}$ \\
\hline 23 & $\begin{array}{l}\text { Presentation of material using words and } \\
\text { pictures/videos is not separate } \\
\text { Presentation of material using video/animation } \\
\text { and interesting narrative }\end{array}$ & 75 & Enough \\
\hline & Cumulative mean & 90.63 & Valid \\
\hline
\end{tabular}

Based on table 4 about the product feasibility level, it was found that the cumulative means of all aspects obtained from media experts is $90.63 \%$, which is stated to be very feasible in the description of the product eligibility level criteria.

\subsection{Respondents' trial results (attractiveness)}

In the trial phase, the module application was carried out to 25 sports teachers. The variables that become aspects of observations about the quality of learning media are recapped in table 4 below.

Table 2. Results of instruments Content Validation or Media Contents for SAC 3 application

\begin{tabular}{|c|c|c|c|}
\hline No & Aspect to measure & $\begin{array}{l}\text { Percentage } \\
(\%)\end{array}$ & Classification \\
\hline 1 & I am happy to use this new application. & 80 & Strongly agree \\
\hline 2 & This new media I use is unattractive. & 29,17 & Strongly disagree \\
\hline 3 & $\begin{array}{l}\text { The material presented in this new media is easy to } \\
\text { understand. }\end{array}$ & 78,33 & Strongly agree \\
\hline 4 & $\begin{array}{l}\text { The size and shape of the letters on this new media } \\
\text { can be read clearly. }\end{array}$ & 46,67 & Disagree \\
\hline 5 & The image on this new media is interesting. & 77,5 & Strongly agree \\
\hline 6 & I understand this medium easily. & 83,33 & Strongly agree \\
\hline 7 & I find it helpful to study independently. & 85 & Strongly agree \\
\hline 8 & I am interested in understanding this learning media. & 79,17 & Strongly agree \\
\hline 9 & $\begin{array}{l}\text { I find it more difficult to understand the material if } \\
\text { using this learning application. }\end{array}$ & 44,17 & Disagree \\
\hline 10 & $\begin{array}{l}\text { I feel that learning objectives can be achieved more } \\
\text { quickly using media. }\end{array}$ & 83,33 & Strongly agree \\
\hline 11 & I am happy to learn drugs using this medium. & 85,83 & Strongly agree \\
\hline
\end{tabular}




\begin{tabular}{llll}
\hline 12 & $\begin{array}{l}\text { My attention was increased when studying the topic } \\
\text { of drugs using the media }\end{array}$ & 90,83 & Strongly agree \\
\hline Cumulative mean score & 81.11 & Strongly agree \\
\hline
\end{tabular}

Based on table 5 of the Likert scale criteria, it is found that the average percentage of all aspects obtained from the attraction test by a large group ( 25 sports teachers) is $81.11 \%$, which is stated to be very attractive so that the print module and android application-based module can be used as a learning medium independently.

\subsection{Discussion}

The SAC 3 application has several advantages over other applications, including; 1) it can be installed or created without advanced programming knowledge, 2) can be utilized to export project html5, 3) display or interface is easy to understand, and 4) does not require a big size of RAM (Random Access Memory) [15] Apart from the advantages of SAC 3 audited above, the SAC 3 apps are also very easy to use especially for active teachers. By using this application, the teacher would be able to be creative effectively in making more innovative learning media. Based on these strengths, the researcher was interested in introducing and developing learning media using SAC 3 application. The following are some suggestions that can be used to optimize the use of this learning media: 1) The material contained in the SAC 3 application media can be used as a reference in physical education learning. 2) Using an android smartphone device with an operating system of at least version 4.4 (KitKat) and above so that the SAC 3 application media can be operated smoothly. 3) At the onset of using this learning media, users are expected to read and understand the instructions for use in the "Guide" menu that has been provided. 4) Users are further expected to read books or other related learning references to increase their knowledge of the material being studied. 5) Further development of the next product is expected not only to be used offline but can be developed with an online system so that developers can update features and materials directly and users can make updates related to these features and materials.

\section{Conclusion}

Android application-based modules on sports subjects specifically on the topic of illegal drugs in high schools are practical media for teachers to use in class teaching. This new media combines different elements that make up the media, namely text, and images. The display of the SAC 3 application media application product which has become the final product of development consists of a cover page, the main menu page, a guide page for teachers and students about using the application, a learning activity page consisting of chapters, a page of chapters consisting of material, practice questions, assessments, answer keys and reference lists, information pages that contain personal data from developers and media advisors of SAC 3 application. Based on the objectives of research and development of modules based on Android applications for Physical Education subjects in drug topic for class X high school students, the following conclusions can be drawn: 1) The SAC 3 application that has been developed using the ADDIE development model (analysis, design, development, implementation, evaluation). 2) The SAC 3 application media developed has been carried out by construct validation by material experts. Based on the validation results, a percentage of 
$75 \%$ is obtained which has a fairly valid classification and is declared feasible by revision. 3) The developed has validated the content by material experts. Based on the results of the validation, it was obtained a percentage of $79.41 \%$ which had a fairly valid classification and was declared feasible by revision. 4) The media for the SAC 3 application developed has been validated by media experts. Based on the validation results obtained a percentage of $90.63 \%$ which has a valid classification and is declared fit for use. 5) The validated and revised SAC 3 application media were tested on 25 sports teachers from around the world. this new media application known as SAC 3 is stated to be very interesting seen from the attractiveness of the teacher's desire to use the application. 6) The attractiveness of the SAC 3 application media can be seen from the results of the trial questionnaire filled out by the teacher. The SAC 3 application media is stated to be very interesting, seen from the results of the trial questionnaire, it is found that a percentage of $81.11 \%$ has a very agreeable classification. Based on these results, the product is suitable for use as a medium to support the learning process and independent learning in the subject of Physical Education on the topic of illegal drugs in grade ten in high schools.

\section{References}

[1] H. C. Jeong and W. Y. So, "Difficulties of online physical education classes in middle and high school and an efficient operation plan to address them," Int. J. Environ. Res. Public Health, vol. 17, no. 19, pp. 1-13, 2020, doi: 10.3390/ijerph17197279.

[2] C. Rapanta, L. Botturi, P. Goodyear, L. Guàrdia, and M. Koole, "Online University Teaching During and After the Covid-19 Crisis: Refocusing Teacher Presence and Learning Activity," Postdigital Sci. Educ., vol. 2, no. 3, pp. 923-945, 2020, doi: 10.1007/s42438-020-00155-y.

[3] S. Dhawan, "Online Learning: A Panacea in the Time of COVID-19 Crisis," J. Educ. Technol. Syst., vol. 49, no. 1, pp. 5-22, 2020, doi: 10.1177/0047239520934018.

[4] S. Androutsellis-Theotokis, D. Spinellis, M. Kechagia, and G. Gousios, "Open source software: A survey from 10,000 feet,” Found. Trends Technol. Inf. Oper. Manag., vol. 4, no. 3-4, pp. 187-347, 2010, doi: 10.1561/0200000026.

[5] S. Simmons, "A stitch in time...," Mach. Prod. Eng., vol. 155, no. 3948, p. 15, 1997, doi: 10.5005/jp-journals-10023-1057.

[6] M. Teräs, J. Suoranta, H. Teräs, and M. Curcher, "Post-Covid-19 Education and Education Technology 'Solutionism': a Seller's Market,” Postdigital Sci. Educ., vol. 2, no. 3, pp. 863-878, 2020, doi: 10.1007/s42438-020-00164-x.

[7] Y. T. Sung, K. E. Chang, and T. C. Liu, "The effects of integrating mobile devices with teaching and learning on students' learning performance: A meta-analysis and research synthesis," Comput. Educ., vol. 94, pp. 252-275, 2016, doi: 10.1016/j.compedu.2015.11.008.

[8] P. R. Subramaniam, "Unlocking the Power of Situational Interest in Physical Education," J. Phys. Educ. Recreat. Danc., vol. 81, no. 7, pp. 38-49, 2010, doi: 10.1080/07303084.2010.10598507.

[9] S. Aydin, S. Yerdelen, S. G. Yalmanci, and V. Göksu, "Academic motivation scale for learning biology: A scale development study," Egit. ve Bilim, vol. 39, no. 176, pp. 425-435, 2014, doi: 10.15390/EB.2014.3678.

[10] R. M. Ryan and E. L. Deci, "Intrinsic and Extrinsic Motivations: Classic Definitions and New Directions," Contemp. Educ. Psychol., vol. 25, no. 1, pp. 54-67, 2000, doi: 10.1006/ceps.1999.1020.

[11] F. H. Weeks, "Behaviour problems in the classroom: A model for teachers to assist learners with unmet emotional needs.," Diss. Abstr. Int., vol. 63, no. 1-A, p. 89, 2000, [Online]. Available: http://ovidsp.ovid.com/ovidweb.cgi?T=JS\&CSC=Y\&NEWS=N\&PAGE=fulltext\&D=psyc4\&AN= 2002-95013-

060\%5Cnhttp://oxfordsfx.hosted.exlibrisgroup.com/oxford?sid=OVID:psycdb\&id=pmid:\&id=doi: $\&$ issn $=0419-4209 \&$ isbn $=\&$ volume $=63 \&$ issue $=1-$ A \& spage $=89 \&$ pages $=89 \&$ date $=2002 \&$ title=Di. 
[12] P. Science, "Jandrić2020 Article TeachingInTheAgeOfCovid-19.pdf," 2020.

[13] S. Brinkmann, "The role of teachers' beliefs in the implementation of learner-centred education in India," p. 319, 2016, [Online]. Available: https://core.ac.uk/download/pdf/79549911.pdf.

[14] R. Tutus Eshananda Hars, Hermawan Pamot, "Journal of Physical Education, Sport , Health and Recreations,” J. Phys. Educ. Sport. Heal. Recreat., vol. 4, no. 2, pp. 102-108, 2014, [Online]. Available: http://journal.unnes.ac.id/sju/index.php/peshr.

[15] V. W. Suryaningtyas, R. A. Nugroho, S. P. Cahyono, M. R. Nababan, and R. Santosa, "Translation Learning Enrichment Using Smart Application Creator 3.0: An Attempt to Design a Mobile Application in Translation for Tourism Purpose Course,” Proc. - 2019 Int. Semin. Appl. Technol. Inf. Commun. Ind. 4.0 Retrosp. Prospect. Challenges, iSemantic 2019, no. October 2020, pp. 542 547, 2019, doi: 10.1109/ISEMANTIC.2019.8884273.

[16] M. Meiers, Handbook of Teacher Education, no. June. 2007.

[17] L. Darling-Hammond, L. Flook, C. Cook-Harvey, B. Barron, and D. Osher, "Implications for educational practice of the science of learning and development," Appl. Dev. Sci., vol. 24, no. 2, pp. 97-140, 2020, doi: 10.1080/10888691.2018.1537791.

[18] A. I. Sari, N. Suryani, D. Rochsantiningsih, and Suharno, "The development of Android-based smartphone learning application on teaching reading comprehension," AIP Conf. Proc., vol. 2194, no. December, 2019, doi: 10.1063/1.5139844.

[19] L. Cheung, "Using the ADDIE Model of Instructional Design to Teach Chest Radiograph Interpretation,” J. Biomed. Educ., vol. 2016, pp. 1-6, 2016, doi: 10.1155/2016/9502572.

[20] A. C. Dumaret and V. Picchi, "Early intervention: Psychosocial outcome of families and children's development,” Ann. Médico-psychologiques, Rev. Psychiatr., vol. 163, no. 6, pp. 476-485, 2005, doi: 10.1016/j.amp.2004.06.015.

[21] A. Glerum, B. Atasoy, and M. Bierlaire, "Using semi-open questions to integrate perceptions in choice models," J. Choice Model., vol. 10, no. 1, pp. 11-33, 2014, doi: 10.1016/j.jocm.2013.12.001.

[22] S. Loeb, S. Dynarski, D. McFarland, P. Morris, S. Reardon, and S. Reber, "Descriptive analysis in education: A guide for researchers," U.S. Dep. Educ. Inst. Educ. Sci. Natl. Cent. Educ. Eval. Reg. Assist., no. March, pp. 1-40, 2017, [Online]. Available: https://eric.ed.gov/?id=ED573325.

[23] M. Arif, Sukaswanto, B. S. Nugraha, and A. Fatah, "Developing module of conventional vehicle fuel systems," J. Phys. Conf. Ser., vol. 1700, no. 1, 2020, doi: 10.1088/1742-6596/1700/1/012084.

[24] R. Stevany Kii Londong, H. Hadromi, and B. Haryadi, "Journal of Vocational Career Education The Effect of the Application of Interprofessional Education (IPE) Simulation Using Role Model Method Towards the Knowledge and Attitude of Nursing Undergraduate Students in Universitas Islam Sultan Agung," Jvce, vol. 4, no. 2, pp. 117-125, 2019, [Online]. Available: https://journal.unnes.ac.id/nju/index.php/jvce.

[25] S. Irfan, "Development of Trainer Sensor as Media Learning Control Systems for Engine Cadets at Politeknik Pelayaran Surabaya," Divers. J., vol. 5, no. 3, pp. 2118-2137, 2020, doi: 10.17648/diversitas-journal-v5i3-1241.

[26] E. Fernández-Gómez, A. Martín-Salvador, T. Luque-Vara, M. A. Sánchez-Ojeda, S. NavarroPrado, and C. Enrique-Mirón, "Content validation through expert judgement of an instrument on the nutritional knowledge, beliefs, and habits of pregnant women," Nutrients, vol. 12, no. 4, 2020, doi: $10.3390 /$ nu12041136.

[27] P. Clave, "EducaciónMédica," vol. 21, no. 6, 2020. 